\title{
Optimization of Concentrated Acid Hydrolysis of Waste Paper Using Response Surface Methodology*1
}

\author{
Ji Young Jung*2, Myung Suk Choi*2, and Jae Kyung Yang*2†
}

\begin{abstract}
Waste paper stands for the major biodegradable organic fraction of most of municipal solid waste. The potential of waste paper for glucose production was investigated in this current work. The pretreatment was accomplished by first subjecting waste paper to disintegration time $(30 \mathrm{~s})$, followed by ink removal of disintegrated waste paper using an deinking agent. Concentrated acid hydrolysis of waste paper with sulfuric acid was optimized to maximize glucose conversion. The concentrated acid hydrolysis conditions for waste paper (disintegrated time: $30 \mathrm{~s}$, deinking agent loading : $15 \mathrm{ml}$ ) were optimized by using central composite design and response surface methodology. The optimization process employed a central composite design, where the investigated variables were acid concentration $(60 \sim 80 \%)$, loading sulfuric acid $(1 \sim 5 \mathrm{ml})$ and reaction time $(1 \sim 5 \mathrm{~h})$. All the tested variables were identified to have significant effects $(p<0.05)$ on glucose conversion. The optimum concentrated acid hydrolysis conditions were acid concentration of $70.8 \%$, loading sulfuric acid of $3.2 \mathrm{ml}$ and a reaction time of $3.6 \mathrm{~h}$. This research of concentrated acid hydrolysis was a promising method to improve glucose conversion for waste paper.
\end{abstract}

Keywords : waste paper, pretreatment, acid hydrolysis, central composite design,response surface methodology

\section{INTRODUCTION}

In recent years, efforts have increased towards a more efficient utilization of renewable municipal solid waste including waste paper (Holtzapple et al., 1992; Lay et al., 1999, Li et al., 2007; Li et al., 2012). Waste paper was usually recycled into low-grade paper products, such as newsprint, paper towels, toilet paper, and cardboard (Park et al., 2004). The shorten- ing of cellulose fibers with repeated reutilization tends to decrease the quality of the paper products (Deng et al., 2010). Because of this phenomenon, the upper limit of waste paperto-paper recycling is said to be $65 \%$. This means that the rest of the paper must be disposed of by incineration or landfill. However, because of environmental restrictions, lack of suitable new

* 1 Received on September 10, 2012; accepted on March 22, 2013

* 2 Division of Environmental Forest Science, Gyeongsang National University, Institute of Agriculture \& Life Sciences, Jinju 660-701, South Korea

† Corresponding author : Jae-Kyung Yang (e mail: jkyang@gnu.ac.kr) 
sites, and concerns about the greenhouse effect, incineration or disposal by landfill may become practically impossible in the near future. Finding new uses for recycled paper is a pressing demand. Among paper, perhaps the most limited in its use is computer printout, which is so superabundant in the business districts of civilized countries (Xiao \& Clarkson, 1997). Generally, waste computer printout is shredded before disposal, in order to keep office matters confidential; this practice has the unintended consequence of shortening the constituent cellulose fibers beyond utilization (Clarkson \& Xiao, 2000; Teghammar et al., 2010). As a consequence, incineration is the usual fate of such materials. However, recent studies have explored other industrial routes. A better way to utilize waste paper would be to converted into bioethanol. Providing that the carbohydrate content of the waste paper is high, it could be converted into bioethanol.

Cellulose, a major building block of waste paper, can be converted enzymatically to reducing sugars including glucose; one use of glucose is fermentation into ethanol. Also, paper sludge after deinking has been traditionally disposed of by burning or landfilling, but could be used as an organic amendment in agricultural soils and filler of erosion control (Chantigny et al., 1999). Basically, the recycling of waste paper can be done by reusing waste paper after pulping them by a machine called pulper and followed by removal of printing ink, a treatment specifically called 'deinking' (Holtzapple et al., 1992).

In order to break down holocellulose for conversion of waste paper to glucose, the cellulose and hemicellulose must be broken down to corresponding monomers (sugars). The hydrolysis step may be carried out either enzymatically or by acid treatment (Romero et al., 2010). Enzymatic hydrolysis is conducted at mild conditions but requires a pretreatment of the raw material to improve the enzymatic digestibility (Sun and Cheng, 2005) and longer retention time (Ingram et al., 1999). Moreover, the production and recovery of enzymes may affect this option from an economic point of view (Iranmahboob et al., 2002). Acid hydrolysis may be carried out either at diluted or concentrated acid conditions. Diluted acid hydrolysis attacks polysaccharides, especially those from the hemicellulose fraction which is easier to hydrolyze than cellulose. In addition, no acid recovery steps are required and acid losses are not important. On the negative side, the yield of glucose from cellulose is low. Concentrated acid hydrolysis enables high ethanol yield because of almost quantitative conversion of cellulose into glucose, although acid recovery is required as well as more resistant reactors.

Acid hydrolysis needs the optimization of process parameters, including concentration of sulfuric acid, reaction time, and reaction temperature, loading substrate for efficient hydrolysis. Ritter et al. (Ritter et al., 1945) showed that the yield of lignin from wood treated with $72 \%$ sulfuric acid for $1 \mathrm{hr}$. showed a nearly constant low value when the temperature was varied from 15 to $30^{\circ} \mathrm{C}$. These same workers reported that with a $2 \mathrm{hr}$. treatment with $72 \%$ sulfuric acid, results showed a maximum yield of reducing sugars at $35^{\circ} \mathrm{C}$. For these reasons it was considered well to begin experiment on saccharification of cellulose using a temperature of $30^{\circ} \mathrm{C}$.

Sulphuric acid is the most commonly used in lignocellulosic residues hydrolysis (Baudel et al., 2005; Larsson et al., 1999) although other mineral acids like hydrochloric acid (Lavarack et al., 2002), nitric acid (Rodríguez-Chong et al., 2004) or phosphoric acid (Romero et al., 2007) have also been assayed. Acid hydrolysis residue included inorganic compound such as ash and lignin. These residue is used primarily as an organic amendment rather than as fertilizers, 
because of mineral nutrient contents. The inorganic compound is affect on the soil improvement (Bolan \& Duraisamy, 2003).

Optimization of hydrolysis conditions involves varying one factor at a time and keeping other variables constant (Mathew \& Nair, 2006). On the other hand, response surface method can effectively use variables simultaneously and determine optimum conditions required (Giovanni, 1983). Response surface methodology is a statistical technique used to model and optimize multiple variables, and it can be used to determine the optimum conditions by combining experimental design with interpolation of first or second order polynomial equations in a sequential testing procedure. Central composite design (CCD) and response surface methodology (RSM) were used to design a systematic experimental method. CCD is well suited for fitting a quadratic surface which usually works well for process optimization. RSM is able to map a response surface over a particular region of interest (Chun et al., 2011). To our knowledge, there are no reports on combined concentrated acid hydrolysis and RSM of waste paper (Um et al., 2011; Rahman et al., 2007; Laopaiboon et al., 2010; Karimi et al., 2006; Sun et al., 2005).

In this research, RSM was applied to determine the optimum concentrated acid hydrolysis conditions. Furthermore, the extent of glucose production was evaluated at the operating conditions determined by RSM analysis.

\section{MATERIALS and METHODS}

\subsection{Raw Material}

Three different types of waste paper were tested : newspaper, old corrugated containers, and computer printout. The waste papers were cut using a standard office shredder to rectangles $0.6 \mathrm{~cm}$ wide and $1.5 \mathrm{~cm}$ long, and were used for pretreatment and concentrated acid hydrolysis (Park et al., 2002). The moisture content of waste paper (newspaper, old corrugated containers, and computer printout) were $3.8 \%, 6.3 \%$ and $5.4 \%$, respectively.

\subsection{Pretreatment of Waste Paper}

Pretreatment was conducted in order to understand the effects of disintegration time and loading deinking agent on computer printout pretreatment efficiency. The pretreatment procedure employed in this study is shown schematically in Fig. 1. To produce pretreated computer printout, $100 \mathrm{~g}$ of shredded computer printout, $10 \%$ $\mathrm{NaOH}(10 \mathrm{~m} \ell)$ and tap water $(1450 \mathrm{~m} \ell)$ were

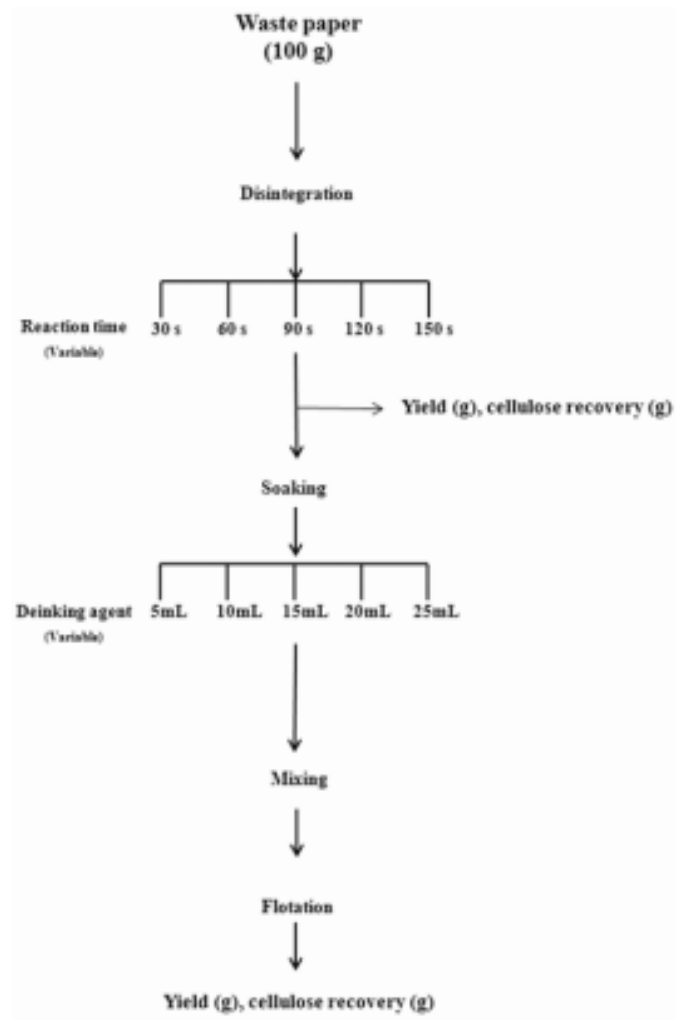

Fig. 1. Schematic of pretreatment procedure for waste paper. 
mixed in a pulp disintegrator (GF7-P61, Hanyoung Co. Ltd., KOREA). The disintegration time was then carried out for $30 \mathrm{~s}, 60 \mathrm{~s}, 90 \mathrm{~s}$, $120 \mathrm{~s}$ and $150 \mathrm{~s}$. After this, the disintegrated computer printout was incubated for $1 \mathrm{hr}$ in a $60^{\circ} \mathrm{C}$ water bath. The amount of deinking agent required to achieve frothing, and hence deinking agent (nonionic surfactant) was 5 to $25 \mathrm{ml}$, which is normally added to commercial deinking agent (provide by Ssangyong paper, Osansi, Korea).

The disintegrated computer printout was diluted in a $5,050 \mathrm{ml}$ flotation cell to a consistency of $1.5 \%$ and conditioned in the presence of the collector. The flotation was then carried out for $20 \mathrm{~min}$. at a stirring speed of $1400 \mathrm{rpm}$. Subsequently, the float (toner particles) and nonfloat (cellulose fibres) products were carefully filtered, dried and stored for analysis of yield and cellulose recovery.

\subsection{Concentrated Acid Hydrolysis of Waste Paper}

\subsubsection{Concentrated Acid Hydrolysis}

Concentrated acid hydrolysis (Table 1) was performed according to the method originally described by Saeman et al. (1945). A first step (concentrated acid hydrolysis) with $60 \sim 80 \%$ (w/w) $\mathrm{H}_{2} \mathrm{SO}_{4}$ at $30^{\circ} \mathrm{C}$ for $1 \sim 5 \mathrm{hr}$. was used.
The media consisted of $300 \mathrm{mg}$ pretreated computer printout/1 $\sim 5 \mathrm{~m} \ell \mathrm{H}_{2} \mathrm{SO}_{4}$ liquor on dry basis. In a second step, the reaction mixture was diluted to $4 \%$ (w/w) $\mathrm{H}_{2} \mathrm{SO}_{4}$ and autoclaved at $121^{\circ} \mathrm{C}$ for $1 \mathrm{hr}$. After reaction was completed, solids were separated from aqueous solution by filtration. The filtrate was analyzed for glucose.

\subsubsection{Design of Experimental}

The effect of three independent variables (acid concentration, loading sulfuric acid and reaction time) on the response (glucose conversion) was studied using a factorial central composite design (CCD) of response surface methodology (RSM), which is a collection of mathematical and statistical techniques for designing experiments, analysing the effects of variables, developing models and optimising the process variables for the optimum response (Ferreira et al., 2009). The experimental data were fit using a low-order polynomial equation to evaluate the effect of each independent variable to the response, which were later analysed to determine the optimum process conditions. For fitting second-order models, CCD was one of the most commonly used RSM (Ferreira et al., 2009). CCD consists of $2^{k}$ factorial points, $2^{k}$ axial points $( \pm a)$, and 6 centre points, where $k$ is the number of independent variables. Each of the variables were

Table 1. Experimental design factors and corresponding values

\begin{tabular}{cccc}
\hline $\begin{array}{c}\text { Coded levels of } \\
\text { experimental factors }\end{array}$ & $\begin{array}{c}\mathrm{X}(1): \\
\text { Acid concentration (\%) }\end{array}$ & $\begin{array}{c}\mathrm{X}(2): \\
\text { Loading sulfuric acid (m) })\end{array}$ & $\begin{array}{c}\mathrm{X}(3) \text { : } \\
\text { Reaction time (hr) }\end{array}$ \\
\hline \hline$-a$ & 60 & 1 & 1 \\
-1 & 65 & 2 & 2 \\
0 & 70 & 3 & 3 \\
1 & 75 & 4 & 4 \\
$a$ & 80 & 5 & 5 \\
\hline
\end{tabular}


investigated at five coded levels $(-a,-1,0,1$, a), as listed in Table 1, and the complete experimental design matrix for this study was shown in Table 2. A total of twenty experiments, including eight for factorial design, six for axial points and six repetitions at the central point, were performed.

\subsubsection{Statistical Analysis}

The CCD experimental results were analyzed using Design-Expert software version 6.0.6, from STAT-EASE, Inc., Minneapolis, USA. Each coefficient in regression equation was calculated and the possible interaction effects of the process variables on the response were obtained. Their significance was checked by variance analysis (ANOVA). Three-dimensional plots were drawn using the RSREG (SAS: statistical analysis system, SAS institute, U.S.A) to illustrate the effects of independent variables on the response. Lastly, two additional replicates were conducted to verify the validity of the predicted optimum values by the program.

Optimization (maximizing glucose convertsion) of the fitted polynomial was determined using numerical optimization contained in the RSREG (SAS: statistical analysis system, SAS institute U.S.A). After optimizing the conditions using RSM, it was validated by extruding the waste paper at the identified optimum acid concentration, loading sulfuric acid and reaction time.

\subsection{Analytical Methods}

The chemical composition of waste paper was determined by the National Renewable Energy Laboratory (NREL) using standard biomass analytical procedures. The glucose content was determined by American Society for Testing and Materials (ASTM) using standard test method for determination of carbohydrates in biomass
Table 2. Central composite experimental design of three variables at five levels for concentrated acid hydrolysis of computer printout

\begin{tabular}{cccc}
\hline \multirow{2}{*}{ Run } & \multicolumn{3}{c}{ Experimental design } \\
\cline { 2 - 4 } & $\mathrm{X}(1)^{1)}$ & $\mathrm{X}(2)^{2)}$ & $\mathrm{X}(3)^{3)}$ \\
\hline 1 & -1 & -1 & -1 \\
2 & -1 & 1 & -1 \\
3 & -1 & -1 & 1 \\
4 & -1 & 1 & 1 \\
5 & 1 & -1 & -1 \\
6 & 1 & 1 & -1 \\
7 & 1 & -1 & 1 \\
8 & 1 & 1 & 1 \\
9 & 0 & -2 & 0 \\
10 & 0 & 2 & 0 \\
11 & 0 & 0 & -2 \\
12 & 0 & 0 & 2 \\
13 & -2 & 0 & 0 \\
14 & 2 & 0 & 0 \\
15 & 0 & 0 & 0 \\
16 & 0 & 0 & 0 \\
17 & 0 & 0 & 0 \\
18 & 0 & 0 & 0 \\
19 & 0 & 0 & 0 \\
20 & 0 & 0 & 0 \\
\hline
\end{tabular}

${ }^{1)}$ Coded value of acid concentration (\%).

${ }^{2)}$ Coded value of loading sulfuric acid (m $\ell$ ).

${ }^{3)}$ Coded value of reaction time (hr).

by gas chromatography. The gas chromatography (Model YL 6100, Younglin, KOREA) system was equipped with a DB-225 capillary column (5 m, $0.25 \mathrm{~mm}$ ID, $0.25 \mathrm{~mm}$ film thickness) (J\& W Scientific, Folsom, CA). Nitrogen was used as the carrier gas. An initial column temperature of $190^{\circ} \mathrm{C}$ was held for $1.0 \mathrm{~min}$. before ramping at $10^{\circ} \mathrm{C}$ per min. up to $220^{\circ} \mathrm{C}$ where it was kept steady for $14 \mathrm{~min}$. The injection port temperature was set at $200^{\circ} \mathrm{C}$, and the FID temperature 
Table 3. Retention times for monosaccharide alditol acetates on DB-225 capillary column

\begin{tabular}{ccc}
\hline Monosaccharide & $\begin{array}{c}\text { Alditol acetate } \\
\text { derivative }\end{array}$ & $\begin{array}{c}\text { Retention time } \\
\text { (minutes) }\end{array}$ \\
\hline \hline Arabinose & Arabitol acetate & 4.11 \\
Xylose & Xylitol acetate & 4.64 \\
Mannose & Mannitol acetate & 6.69 \\
Galactose & Galactitol acetate & 7.08 \\
Glucose & Glucitol acetate & 7.52 \\
Inositol & Inositol acetate & 7.92 \\
\hline
\end{tabular}

was set at $250^{\circ} \mathrm{C}$. Total column flow was $50 \mathrm{ml}$ /min., sample linear velocity through the column was $78 \mathrm{~cm} / \mathrm{s}$, column flow was $3.0 \mathrm{~m} / / \mathrm{min}$., and $2 \mu l$ samples were injected with a split ratio of 15:1. The retention times for each monomer can be found in Table 3 .

The glucose conversion after concentrated acid hydrolysis was calculated by Eq. (1):

$\%$ Glucose conversion

$=\frac{\text { Weight of glucosein acid hydrolysate }(\mathrm{g})}{\text { Weight of glucose in pretreatedcomputer printout }(\mathrm{g})} \times 100$

\section{RESULTS and DISCUSSION}

\subsection{Chemical Composition of Waste Paper}

The waste paper was divided into: corrugated paper and paper bags, newspaper, coated paper, cardboard and uncoated, wood-free paper (Jannick et al., 2007). The chemical composition of waste paper was shown in Table 4.

Newspaper was found to contain, cellulose (57.1\%), hemicellulose $(8.4 \%)$, lignin $(17.2 \%)$ and ash $(6.2 \%)$. The results obtained here were similar to earlier studies, where lignin and holocellulose content in newspaper were found to be $16 \sim 22 \%$ and $60 \sim 75 \%$, respectively (Lee et al.,
2000; Torget et al., 2000). Also, Table 4 shows the chemical composition of the old corrugated containers. Experimental results show that about $47.5 \%$ of the oven-dry cardboard weight corresponds to cellulose, a proportion lower than the one reported for Yáñez et al. (59.7\%) (Yáñez et al., 2004). Computer printout main contained $68.2 \%$ holocellulose $(59.2 \%$ cellulose and $9.0 \%$ hemicellulose) and $17.5 \%$ ash content. Among three sources of waste paper including computer printout, newspaper and old corrugated containers, computer printout gave the highest values of cellulose. Carbohydrate (cellulose and hemicellulolose) was higher than that reported for other lignocellulosic material like wood, agriculture residue (Chen et al., 2007; Mamma et al., 1995; Gnansounou et al., 2005; Li et al., 2010, Wiselogel et al., 1996). The high cellulose content in the computer printout made it a substrate of choice for glucose production.

\subsection{Pretreatment of Computer Printout}

Computer printout was defined as that paper used in plain paper copiers; waste computer printout denotes plain paper copiers after printing in a printer or copy machine. computer printout contain toner or ink-related compounds on the surface of paper (Park et al., 2004). The ink fixed on the repeating units of cellulose backbone block the sequential hydrolysis of paper and inhibited the hydrolysis kinetics significantly (Kuhad et al., 2010). To determine their effects on yield and cellulose recovery, computer printout were used for pretreatment. The purpose of this pretreatment was to remove the toner and ink-related compounds in computer printout. At first attempt at pretreatment, the disintegration condition was tested at room temperature during five different disintegration time 30 150 s. Fig. 2 shows the yield and cellulose recovery resulting from pretreatment at different 
Optimization of Concentrated Acid Hydrolysis of Waste Paper Using Response Surface Methodology

Table 4. Chemical composition of waste paper ${ }^{11}$

\begin{tabular}{|c|c|c|c|}
\hline \multirow{2}{*}{ Composition } & \multicolumn{3}{|c|}{$\%$ Dry weight } \\
\hline & Newspaper & Old corrugated containers & Computer printout \\
\hline Extractives & $9.7 \pm 0.3^{2)}$ & $8.8 \pm 0.4^{2)}$ & $9.2 \pm 0.8^{2)}$ \\
\hline Cellulose as glucose & $57.1 \pm 0.1$ & $47.5 \pm 0.1$ & $59.2 \pm 0.2$ \\
\hline Hemicellulose $^{3)}$ as & 8.4 & 10.6 & 9.0 \\
\hline Xylose & 5.5 & 6.8 & 7.6 \\
\hline Galactose & 0.8 & 0.4 & 0.0 \\
\hline Arabinose & 0.8 & 0.7 & 0.4 \\
\hline Mannose & 1.3 & 2.8 & 1.0 \\
\hline Acid insoluble lignin & $14.3 \pm 0.2$ & $14.5 \pm 0.1$ & $3.0 \pm 0.1$ \\
\hline Acid soluble lignin & $2.9 \pm 0.0$ & $3.6 \pm 0.0$ & $3.4 \pm 0.0$ \\
\hline Ash & $6.2 \pm 0.2$ & $12.7 \pm 0.2$ & $17.5 \pm 0.3$ \\
\hline Protein & $0.5 \pm 0.1$ & $0.9 \pm 0.1$ & $0.4 \pm 0.1$ \\
\hline
\end{tabular}

${ }^{1)}$ Data in the table was based on oven dry samples.

${ }^{2)}$ Mean values of triplicate samples with standard deviations.

${ }^{3)}$ Hemicellulose : xylose + galactose + arabinose + mannose.

disintegration time. The recovered computer printout samples have significantly reduced yield $(p$ $<0.05)$ and cellulose recovery compared to the untreated computer printout. During disintegration, yield was decreased by $7.6 \%$, and $12.1 \%$ of cellulose recovery. The yield ranged between 93.0 and $92.4 \%$, cellulose recovery ranged between 49.6 and $41.9 \%$. The maximum cellulose recovery in disintegrated computer printout was obtained at disintegration time $30 \mathrm{~s}$. In flotation deinking lines, ink removal exceeds $80 \sim 90 \%$ but a modest ink separation selectivity ( $\mathrm{Zhu}$ et al., 2005) results in high losses (15 30\%) of mineral fillers and cellulosic material (Beneventi et al., 2007).

In flotation deinking process, mechanisms governing inter fibre and bubble/fibre interaction in aerated pulp slurries and their contribution to the fibre yield during the flotation deinking process, are not fully understood.

Experimental data showing the effects of various loading deinking agent on yield and cellulose recovery are summarized in Fig. 3. As this

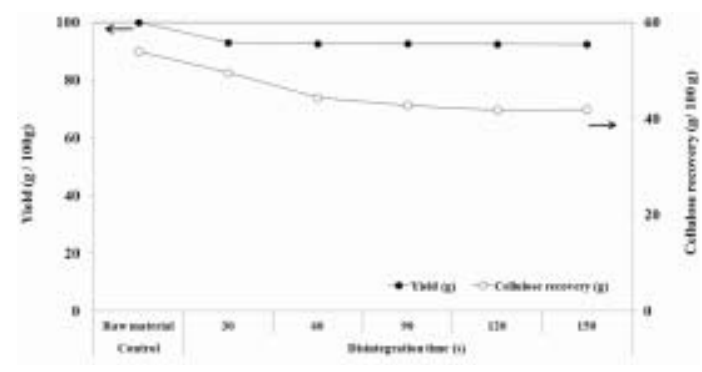

Fig. 2. Effect of disintegration time on the pretreatment.

Fig. 3 suggests, yield of disintegrated computer printout decreased with increased loading deinking agent. The cellulose recovery attained their maximum at approximately $15 \mathrm{~m} \ell$ of deinking agent per $100 \mathrm{~g}$ of computer printout.

The practice of caustic pulping originates from the success in the deinking of computer printout. However, the computer printout was printed with oil-based inks. Such inks were removed from the paper by a saponification reaction (Mckinney, 2005) 


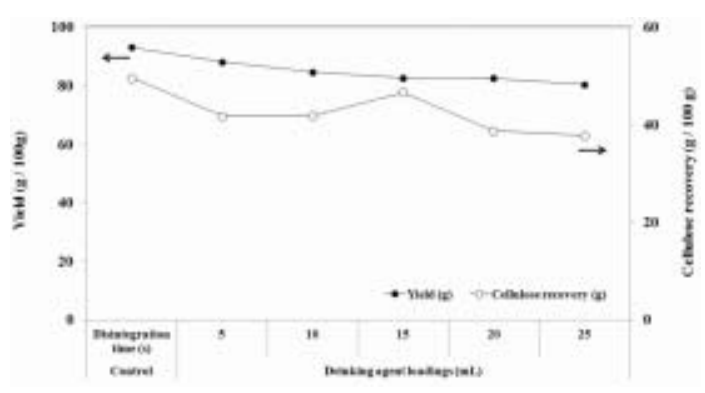

Fig. 3. Effect of loading deinking agent on the pretreatment.

\subsection{Modeling and Optimization of Concentrated Acid Hydrolysis}

The conditions of the system were optimized using the CCD based on the model obtained and the input criteria. The optimization of concentrated acid hydrolysis was carried out based on the three variables (acid concentration, loading sulfuric acid and reaction time) which were in the range of experimental runs.

The experimental design and corresponding responses of the dependent variables (glucose conversion) are listed in Table 5. Central composite design was used to develop correlation between the concentrated acid hydrolysis variables to the glucose conversion. The glucose conversion was found to range between 30.9 and $94.4 \%$. Runs $15 \sim 20$ at the centre point were used to determine the experimental error.

According to the sequential model, sum of squares, the models were selected based on the highest polynomials order and were not aliased. For responses of glucose conversion, the quadratic model was selected, as suggested by used software. The final empirical models in terms of coded factors are given by Eq. (2) where $\mathrm{Y}$ was glucose conversion:
Table 5. Experimental data for concentrated acid hydrolysis of computer printout

\begin{tabular}{|c|c|c|c|c|}
\hline \multirow{2}{*}{ Run - } & \multicolumn{3}{|c|}{ Experimental design } & \multirow{2}{*}{$\begin{array}{c}\text { Dependent variables } \\
\text { Glucose conversion }(\%) \\
\end{array}$} \\
\hline & $X(1)^{1)}$ & $\mathrm{X}(2)^{2)}$ & $\mathrm{X}(3)^{3)}$ & \\
\hline 1 & -1 & -1 & -1 & 50.1 \\
\hline 2 & -1 & 1 & -1 & 40.7 \\
\hline 3 & -1 & -1 & 1 & 30.9 \\
\hline 4 & -1 & 1 & 1 & 38.5 \\
\hline 5 & 1 & -1 & -1 & 38.5 \\
\hline 6 & 1 & 1 & -1 & 54.7 \\
\hline 7 & 1 & -1 & 1 & 41.4 \\
\hline 8 & 1 & 1 & 1 & 48.6 \\
\hline 9 & 0 & -2 & 0 & 34.6 \\
\hline 10 & 0 & 2 & 0 & 54.8 \\
\hline 11 & 0 & 0 & -2 & 62.7 \\
\hline 12 & 0 & 0 & 2 & 94.4 \\
\hline 13 & -2 & 0 & 0 & 35.1 \\
\hline 14 & 2 & 0 & 0 & 49.9 \\
\hline 15 & 0 & 0 & 0 & 82.0 \\
\hline 16 & 0 & 0 & 0 & 82.4 \\
\hline 17 & 0 & 0 & 0 & 82.8 \\
\hline 18 & 0 & 0 & 0 & 82.3 \\
\hline 19 & 0 & 0 & 0 & 82.4 \\
\hline 20 & 0 & 0 & 0 & 82.5 \\
\hline & $\begin{array}{l}\text { Yean ab } \\
\text { for re }\end{array}$ & $\begin{array}{l}\text { solute e } \\
\text { plication }\end{array}$ & & $0.26 \%$ \\
\hline
\end{tabular}

${ }^{1)}$ Coded value of acid concentration (\%).

${ }^{2)}$ Coded value of loading sulfuric acid (m $\ell$ ).

${ }^{3)}$ Coded value of reaction time (hr).

$$
\begin{aligned}
& \mathrm{Y}= \\
& \quad \beta_{0}+\beta_{1} \mathrm{X}(1)+\beta_{2} \mathrm{X}(2)+\beta_{3} \mathrm{X}(3) \\
& +\beta_{11} \mathrm{X}(1)^{2}+\beta_{12} \mathrm{X}(1) \mathrm{X}(2)+\beta_{22} \mathrm{X}(2)^{2} \\
& +\beta_{13} \mathrm{X}(1) \mathrm{X}(3)+\beta_{23} \mathrm{X}(2) \mathrm{X}(3)+\beta_{33} \mathrm{X}(3)^{2}
\end{aligned}
$$

where $X(1), X(2)$ and $X(3)$ were the acid concentration, loading sulfuric acid and reaction time, respectively. The experimental data were used to calculate the coefficients of the second- 
Optimization of Concentrated Acid Hydrolysis of Waste Paper Using Response Surface Methodology

order polynomial equation.

The response surface regression and models were expressed in terms of coded variables, without taking into account the statistically nonsignificant terms at $a=0.05$. In other words, only the model terms with $p$-values less than 0.05 were determined to be significant to the model equations. The coefficients $\beta$, are displayed in Table 6 . The quality of the models developed was evaluated based on the correlation coefficient $\mathrm{R}^{2}$, and also the standard deviation values. The $\mathrm{R}^{2}$ was found to be 0.7830 . This indicates that $78.3 \%$ of the total variation in glucose conversion was attributed to the experimental variables studied. The regression model for the glucose conversion was presented in Eq. (3). Additionally, the p-values suggest that the variables $\mathrm{X}(1)$ had significant effects on the glucose conversion.

$$
\begin{aligned}
& \mathrm{Y}= \\
& -2926.694167+83.507167 \mathrm{X}(1) \\
& +45.730000 \mathrm{X}(2)-4.245000 \mathrm{X}(3) \\
& -0.615033 \mathrm{X}(1)^{2}+0.630000 \mathrm{X}(1) \mathrm{X}(2) \\
& -14.825833 \mathrm{X}(2)^{2}+0.455000 \mathrm{X}(1) \mathrm{X}(3) \\
& +1.000000 \mathrm{X}(2) \mathrm{X}(3)-4.363333 \mathrm{X}(3)^{2}
\end{aligned}
$$

The effects of the three variables (acid concentration, loading sulfuric acid and reaction time) on glucose conversion were analyzed using RSM. The data analysis was developed by fitting the experimental data in a smooth curve, which was plotted by calculation of the specific predicted response. Three-dimensional response surface and contour plots were generated to investigate the interactive effects of any two variables on the response by evaluating two variables at a time while holding the other one constant at central level. A three-dimensional plot can give a clearer geometrical representation of the nature and extent of the interaction between the variables and response within the experi-
Table 6. Regression coefficients for the response surface and $p$-values

\begin{tabular}{ccc}
\hline Coefficient & Parameter estimate & $p$-value \\
\hline$\beta_{0}$ & -2926.694167 & 0.0207 \\
$\beta_{1}$ & 83.507167 & 0.0133 \\
$\beta_{2}$ & 45.730000 & 0.6928 \\
$\beta_{3}$ & -4.245000 & 0.9706 \\
$\beta_{11}$ & -0.615033 & 0.0099 \\
$\beta_{12}$ & 0.630000 & 0.6874 \\
$\beta_{22}$ & -14.825833 & 0.0118 \\
$\beta_{13}$ & 0.455000 & 0.7708 \\
$\beta_{23}$ & 1.000000 & 0.8979 \\
$\beta_{33}$ & -4.363333 & 0.3677 \\
R-square & \multicolumn{2}{c}{0.7830} \\
\hline
\end{tabular}

mental range studied. The relationship between the response and controlled variables was visualized using the response surface or contours plots. Graphic representation of the response surface shown in Fig. 4(a c) helps visualize the effects of various variables. Response surfaces plots of glucose conversion was obtained using predicted values from the fitted model, by keeping one of the independent variables fixed at the optimum value while modifying the other two variables.

Fig. 4(a) represents the three-dimensional response surface plot of glucose conversion at a reaction time of $3.6 \mathrm{hr}$ to investigate the interactive effect of acid concentration and loading sulfuric acid. At different acid concentration, the glucose conversion reaches a maximum value at approximate $70.8 \%$. At different acid concentration and loading sulfuric acid, the glucose conversion reaches a maximum value at approximate $3.6 \mathrm{hr}$ and slightly decreases above that value (Fig. 4(b) and Fig. 4(c)). This study has revealed that concentrated acid hydrolysis at a moderate acid concentration around $70.8 \%$ maximum glucose conversion within the range 68 $78 \%$ and reaction time from 2 to $5 \mathrm{hr}$. 

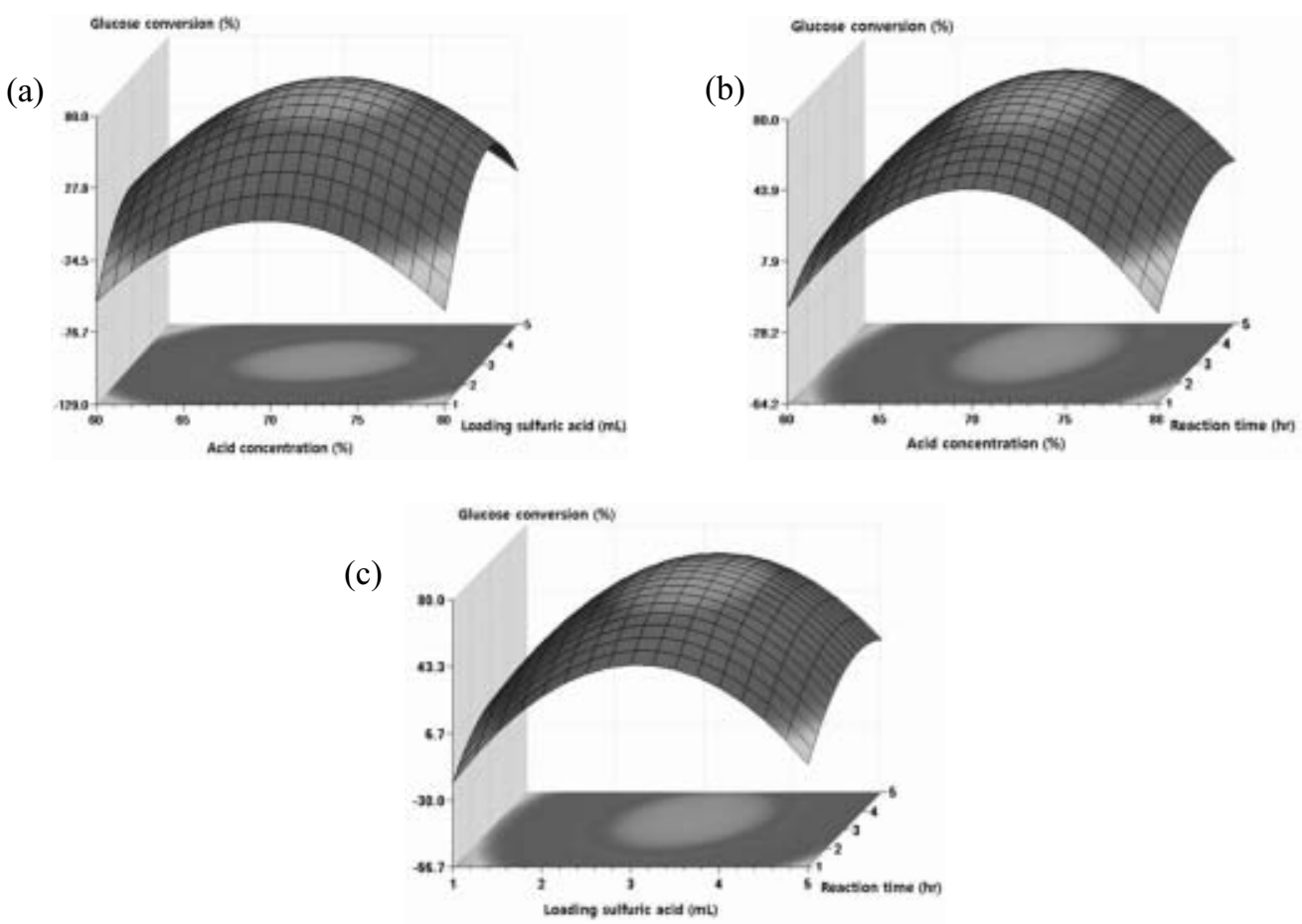

Fig. 4. Response surface plots show the effects of acid concentration and loading sulfuric acid (a); acid concentration and reaction time (b); loading sulfuric acid and reaction time (c). The value of the time variable was fixed at the optimal point.

The optimal conditions for concentrated acid hydrolysis were extracted by Design-Expert software though a graphical optimization. Taking efficiency into consideration, the optimum operating parameters were found to be: $\mathrm{X}(1)=$ $70.8 \%, \mathrm{X}(2)=3.2 \mathrm{ml}, \mathrm{X}(3)=3.6 \mathrm{hr}$. Under these conditions, confirmation experiments were conducted in five replicates. The observed mean glucose conversion was found to be largely consistent with the predicted values. At the same time, it is further confirmed the rationality and practicability of optimal conditions for concentrated acid hydrolysis in this work. In these conditions, the model predicted glucose conversion of $94.4 \%$.

To confirm these results, experimental runs were conducted under optimized conditions and glucose conversion of $92.1 \%$ was attained. These results showed that the model fitted well the experimental data and thus described well the region studied.

\section{CONCLUSION}

There use of waste paper for the production of glucose seems feasible approach for energy conservation and waste minimization.

Concentrated acid hydrolysis of pretreated computer printout (disintegration time: $30 \mathrm{~s}$, loading deinking agent : $15 \mathrm{~m}$ ) was successful in enhancement of glucose conversion. The optimum concentrated acid hydrolysis condition for glucose conversion was determined to be acid concentration $70.8 \%$, loading sulfuric acid $3.2 \%$ 
and a reaction time $3.6 \mathrm{hr}$. The experimental value was well within the estimated value of the model. By operating the pretreatment at optimum conditions, it avoids using the longest possible time and highest sulfuric acid loading, subsequently reduces the overall production cost.

The research is needed to make this process economically feasible. Ultimately the optimal hydrolysis conditions for the glucose recovery at the laboratory scale may potentially be scaled up to the production level.

This research of concentrated acid hydrolysis was an economical method to improve glucose conversion for waste paper.

\section{ACKNOWLEDGEMENT}

This study was carried out with the support of "Research Center for Ecological Restoration in Damaged land (project No. S211212L0504)" provide by Korea Forest Service, Republic of Korea and partially supported by "Development of Application Technology using Succinic Acid Derivatives (project No. 10033530; Ministry of Knowledge Economy)".

\section{REFERENCES}

1. Baudel, H. M., Zaror, C. and C. A. M. de Abreu. 2005. Improving the value of sugarcane bagasse wastes via integrated chemical production systems: an environmentally friendly approach. Ind. Crops Prod. 21: 309 315.

2. Beneventi, D., Benesse, M., Carre, B., Julien Saint Amand, F., and L. Salgueiro. 2007. Modelling deinking selectivity in multistage flotation systems. Sep. Purif. Technol., 54: $77 \sim 87$.

3. Bolan, N. S. and V. P., Duraisamy. 2003. Role of inorganic and organic soil amendments on immobilisation and phytoavailability of heavy metals: a review involving specific case studies. Aust. J. Soil Res. 41: $533 \sim 555$.

4. Chantigny, M. H., Angers, D. A., and C. J. Beauchamps. 1999. Aggregation and organic matter decomposition in soils amended with de-inking paper sludge Soil Science Society of America Journal, 63: 1214 1221.

5. Chen, Y., R. R. Sharma-Shivappa, D. Keshwani, and C. Chen. 2007. Potential of agricultural residues and hay for bioethanol production. Appl. Biochem. Biotechnol 142: 276 290.

6. Chun S. G., T. T. Hui, T. L. Keat, and B. Nicolas. 2011. Evaluation and optimization of organosolv pretreatment using combined severity factors and response surface methodology. Biomass and Bioenergy 35(9): 4025 $\sim 4033$.

7. Clarkson, W. W. and W. Xiao. 2000. Benchscale anaerobic bioconversion of newsprint and office paper. Water Sci. Technol. 41: $93 \sim 100$.

8. Deng, L., L. Xiao, Y. Tang, and X. Song. 2010. Effects of pretreatment on enzymatic hydrolysis of cellulose for waste paper. J. Beijing Forestry Univ. 32: 170 175 (in Chinese).

9. Ferreira, S., A. P. Duarte, M. H. L. Ribeiro, J. A. Queiroz, and F. C. Domingues. 2009. Response surface optimization of enzymatic hydrolysis of Cistus ladanifer and Cytisus striatus for bioethanol production. Biochemical Engineering Journal 45: 192 200.

10. Giovanni, M. 1983. Response surface methodology and product optimization. Food Technol. November: $41 \sim 45$.

11. Gnansounou, E., A. Dauriat, and C. E. Wyman. 2005. Refining sweet sorghum to ethanol and sugar: economic trade-offs in the context of North China. Bioresour. Technol. 96: $985 \sim 1002$.

12. Holtzapple, M. T. and J. E. Lundeen. 1992. 
$\mathrm{R}$ Sturgis Pretreatment of lignocellulosic municipal solid waste by ammonia fiber explosion (AFEX) Appl. Biochem. Biotechnol. 34/35: 5 21.

13. Ingram, L .O., H. C. Aldrich, C. C. Borges, T. B. Causey, A. Martínez, and F. Morales. 1999. Enteric bacterial catalysts for fuel ethanol production. Biotechnol. Prog. 15(5): $855 \sim 866$.

14. Iranmahboob, J., F. Nadim, and S. Monemi. 2002. Optimizing acid-hydrolysis: a critical step for production of ethanol from mixed wood chips. Biomass and Bioenergy 22: $401 \sim 404$.

15. Jannick, H., Schmidt, P. Holm, A. Merrild, and P. Christensen. 2007. Life cycle assessment of the waste hierarchy-A Danish case study on waste paper, Waste Management 27(11): 1519 1530.

16. Karimi, K., S. Kheradmandinia, and M. J. Taherzadeh. 2006. Conversion of rice straw to sugars by diluteacid ydrolysis. Biomass and Bioenergy 30: 247 253.

17. Kuhad, R. C., G. Mehta, R. Gupta, and K. K. Sharma. 2010. Fed batch enzymatic saccharification of newspaper cellulosics improves the sugar content in the hydrolysates and eventually the ethanol fermentation by Saccharomyces cerevisiae. Biomass and Bioenergy 34(8): 1189 1194.

18. Laopaiboon, P., A. Thani, and V. Leelavatcharamas. 2010. L. Laopaibooncid hydrolysis of sugarcane bagasse for lactic acid production ioresour. Technol. 101: 1036 1043.

19. Larsson, S., E. Palmqvist, B. Hahn-Hägerdal, C. Tenborg, K. Stenberg, G. Zacchi, and N. O. Nilvebrant. 1999. The generation of fermentation inhibitors during dilute acid hydrolysis of softwood. Enzyme Microb Technol. 24: $151 \sim 159$.

20. Lavarack, B. P., G. J. Griffin, and D. Rodman. 2002. The acid hydrolysis of sugarcane bagasse hemicellulose to produce xylose, arabinose, glucose and other products. Biomass and Bioenergy 23: 367 380 .

21. Lay, J. J. and Y. J. Lee. 1999. T. Noike Feasibility of biological hydrogen production from organic fraction of municipal solid waste. Water. Res. 33(11): 2579 2586 .

22. Lee, Y. Y., Z. Wu, and R. W. Torget. 2000. Modeling of countercurrent shrinkingbed reactor in dilute-acid hydrolysis of lignocellulosic biomass. Bioresour. Technol. 71: $29 \sim 39$.

23. Li A., B. Antizar-Ladislao, and M. Khraisheh. 2007. Bioconversion of municipal solid waste to glucose for bioethanol production. Bioprocess. Biosyst. Eng. 30: 189 196.

24. Li, C., B. Knierim, C. Manisseri, R. Arora, H. V. Scheller, M. Auer. 2010. Comparison of dilute acid and ionic liquid pretreatment of switchgrass: biomass recalcitrance, delignification and enzymatic saccharification. Bioresour. Technol. 101: 4900 4906.

25. Li, S., X. Zhang, and J. M. Andresen. 2012. Production of fermentable sugars from enzymatic hydrolysis of pretreated municipal solid waste after autoclave process. Fuel 92: $84 \sim 88$.

26. Mamma, D., P. Christakopoulos, D. Koullas, D. Kekos, B. J. Macris, and E. Kouki. 1995. An alternative approach to the bioconversion of sweet sorghum carbohydrates to ethanol. Biomass and Bioenergy 8(2): 99 $\sim 103$.

27. Mathew P. and K. G. R. Nair. 2006. Ensilation of shrimp waste by Lactobacillus fermentum. Fish Technol. 43: 59 64.

28. Mckinney, R. W. J. 1995. Technology of paper recycling, 1st ed., Chapman \& Hall, Glasgow, UK. pp: $130 \sim 156$.

29. Park, E. Y., P. N. Anh, and N. Okuda. 2004. Bioconversion of waste office paper to $\mathrm{L}(+)$-lactic acid by the filamentous fungus 
Optimization of Concentrated Acid Hydrolysis of Waste Paper Using Response Surface Methodology

Rhizopus oryzae, Bioresour. Technol. 93: $77 \sim 83$.

30. Park, E. Y., Y. Ikeda, and N. Okuda. 2002. Empirical evaluation of cellulase on enzymatic hydrolysis of waste OA paper. Biotechnol. Bioprocess Eng. 7: 1 6.

31. Rahman, S. H. A., J. P. Choudhury, A. L. Ahmad, and A. H. 2007. Kamaruddin Optimization studies on acid hydrolysis of oil palm empty fruit bunch fiber for production of xylose. Bioresource Technol. 98: 554 559.

32. Ritter, G. J., R. M, Seborg. and R. L. Mitchell. 1932. Factors Affecting quantitative determination of lignin by 72 per cent sulfuric acid method. Ind. Eng. Chem. Anal. Ed. 4(2): 202 204.

33. Rodríguez-Chong, A., J. A. Ramírez, G. Garrote, and M. Vázquez. 2004. Hydrolysis of sugar cane bagasse using nitric acid: a kinetic assessment. J. Food Eng. 61: 143 152.

34. Romero, I., E. Ruiz, E. Castro, and M. Moya. 2010. Acid hydrolysis of olive tree biomass. Chemical Engineering Research and Design 88: 633 640 .

35. Romero, I., S. Sánchez, M. Moya, E. Castro, E. Ruiz, and V. Bravo. 2007. Fermentation of olive tree pruning acidhydrolysates by Pachysolen tannophilus. Biochem Eng. J. 36: $108 \sim 115$.

36. Saeman, J. F., J. L. Bubl, and E. E. Harris. 1945. Quantitative Saccharification of Wood and Cellulose. Ind. Eng. Chem. Anal. Ed. 17 (1): $35 \sim 37$.

37. Sun, Y. and J. J. Cheng. 2005. Dilute acid pretreatment of rye straw and bermudagrass for ethanol production. Bioresour. Technol. 96: $1599 \sim 1606$.

38. Teghammar, A., J. Yngvesson, M. Lundin, M. J. Taherzadeh, and I. S. Horváth. 2010. Pretreatment of paper tube residuals for improved biogas production. Bioresour. Technol. 101: $1206 \sim 1212$.

39. Torget, R. W., J. S. Kim, and Y. Y. Lee. 2000. Fundamental aspects of dilute acid hydrolysis of hardwood carbohydrates: cellulose hydrolysis. Ind. Eng. Chem. Res. 39: $2817 \sim 2825$.

40. Um, B. H. and S. H. Bae. 2011. Statistical methodology for optimizing the dilute acid hydrolysis of sugarcane bagasse. Korean J. Chem. Eng. 28(5): 1172 1176.

41. Wiselogel, A., S. Tyson, and D. Johnson. 1996. Biomass feedstock resources and composition. In: Wyman, C.E. (Ed.), Handbook on Bioethanol: Production and Utilization. Taylor \& Francis, Washington, DC: $105 \sim 118$.

42. Xiao, W. and W. W. Clarkson. 1997. Acid solubilization of lignin and bioconversion of treated newsprint to methane. Biodegradation 8: $61 \sim 66$.

43. Yáñez, R., J. L. Alonso, and J. C. Parajó. 2004. Production of hemicellulosic sugars and glucose from residual corrugated cardboard, Process Biochem. 39: 1543 1551.

44. Zhu, J. Y., F. Tan, K. L.Scallon, Y. Zhao, and Y. Deng. 2005. Deinking selectivity (Zfactor): a newparameter to evaluate to evaluate the performance of flotation deinking process. Sep. Purif. Technol. $43: 33 \sim 41$. 